\title{
The potential of integrating social media as a learning tool among international graduate students in Beijing
}

Kayange, Jimmy Jaston

Beijing Normal University, China (Jastonjimmy@yahoo.com)

Msiska, Masauko $\longrightarrow$

Beijing Normal University, China (masamsiska@yahoo.com)

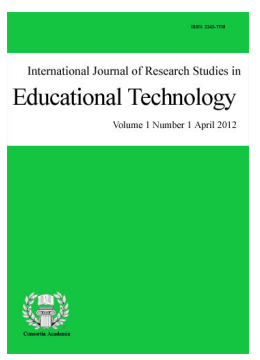

ISSN: $2243-7738$ Online ISSN: 2243-7746

Received: 17 January 2016 Available Online: 7 March 2016

\section{Abstract}

The study aimed at exploring social media usage by international graduate students in the faculty of education at a university in Beijing. The rationale was to find out how students use social media and the challenges associated with such media usage. This would help educators to effectively integrate social media in learning. The study found that students use social media to get social support, to collaborate on academic work and to share necessary information pertaining to their course work. The study also found that social media give equal voice to students unlike in the face to face discussions. The study further found that it is difficult to access some of the social media platforms. Again, it was found that social media reduces interpersonal skills, compromises one's academic performance and allows abuse by some users.

Keywords: academic; theory of connectivism; media platform; wechat 


\section{The potential of integrating social media as a learning tool among international graduate students in Beijing}

\section{Introduction}

The $21^{\text {st }}$ century has witnessed extreme advancement in information technology. This technological progression has resulted into proliferation and usage of social media websites and platforms. Social media provides a variety of tools, commonly known as web 2.0 that educators can use to engage students and enhance essential skills (Lenartz, 2012). According to Halligan (as cited in May, 2015), social media is electronic communication that lets users create online communities and share information. Social media generally includes but not limited to Facebook, LinkedIn, YouTube, Twitter, MySpace, Instagram, Skype, WeChat and Tencent. Social media allows people to maintain connection with friends and family and disseminate thoughts and information to a potentially large audience in a very short period of time (Albert, 2015). Social media is mostly used by the youth which comprises a large number of students (Bal, Grewal, Mills, \& Ottley, 2015). Most of these youths are digital natives, a generation that has never seen the world without the internet (West, Moore, \& Barry, 2015). These scholars further assert that social media has become an integral part of the youth's lives; it defines their identity and facilitates community building.

In relation to education, several scholars have emphasized the effect of social media on the learners. According to Miron and Ravid (2015), social media has changed the nature of the $21^{\text {st }}$ century learners by exposing them to a variety of information. Blaschke (2014) and Luo (2010), share the view that social media facilitates interaction among students by providing a dynamic platform that enables connections and social support, collaboration, discussions and organization of activities and events which is a crucial component of academic experiences. Blaschke (2014) believes social media brings with it the freedom for learners to connect and collaborate outside of institutional boundaries as well as to gain practical experiences for the workforce. Johnson and Maddox (2012) go on to say that social media facilitates curriculum instruction, mentorship and access to expertise. Albert (2015) further states that social media platforms can facilitate learning experiences that may be cumbersome, time consuming or not possible in a traditional setting. However, according to Nkhoma et al. (2015) social media can compromise the learning process if for example students lack the desire or willingness to use social media for learning purposes. Students may spend more of their time on social media chatting with friends and spend less on academic activities. McEwan (2011), contends and states that social media may result into information overload and one would argue that this may confuse students on the rightful information to use.

\subsection{The Extent of Social Media Usage}

Even though social media is a recent breakthrough, its usage has proliferated to great heights. It is believed that to date over 80 percent of faculty use social media (Blaschke, 2014). It is also believed that college students form a large proportion of users of social media networks (Duta \& Mertinez-Rivera, 2014). Scholars claim that as early as 2007 , over $94 \%$ of students engaged in social media to connect and socialize with friends and family (Bal, Grewal, Mills, \& Ottley, 2015), and about 45\% of them use social media sites at least once a day (Sponcil $\&$ Gitimu, 2013). These figures are possibly rising each passing year especially that technological expansion and internet accessibility is rising each day. Given that a high percentage of faculty and students is using social media, educators need to integrate these platforms in the teaching and learning so that learning is congruent with their life style. However, one would argue that to maximize the potential of using social media platforms for purposes mentioned above, one must first understand the kind of social platforms and the extent to which students use and how they use such platforms. This would help instructors to effectively and efficiently integrate social media in learning. Nonetheless, Demirbilek (2015), notes that little is known about the use of social media 
The potential of integrating social media as a learning tool among international graduate students in Beijing

in academia. Jackson (as cited in Ding \& Stapleton, 2015) particularly observes that even though social networks have become indispensable among college students, research into their impact is still an emerging area. Therefore, there is a need to understand how students use these social media networks before any consideration to integrate them into the teaching and learning process is made. The underlying purpose of this study is therefore to explore how international graduate students in the faculty of education at a university in Beijing use social media platforms. To achieve this purpose, these questions are explored; how do students use social media? What is the benefit of social media usage? What are the challenges faced when using social media?

\section{Theoretical Framework: Theory of Connectivism}

This study is grounded in the theory of Connectivism. Connectivism is a learning theory that explains how internet technologies have created new opportunities for people to learn and share information across the World Wide Web and among themselves (Siemens, 2004). It is characterized as the enhancements of how a student learns with the knowledge and perception gained through the addition of a personal network (Siemens, 2004). Siemens notes that it is only through these personal networks that the learner can acquire the view point and diversity of opinions to learn to make critical decisions. This view is supported by Duke, Harper, and Johnston (2013) who argue that because it is impossible to experience everything, the learner can share and learn through collaboration. All these however seem to support the view of social constructivism which suggests that humans generate knowledge and meaning through interaction with others. This is closely related to Dron and Anderson (2015) argument that learning is inherently a social process where we learn from each other and that in most cases this learning is mediated by technologies. This learning could therefore be facilitated among others through connections in social media where learners share information and learn from each other. A key feature of connectivism is that learning can happen across peer networks that take place online (Siemens, 2004).

\section{Methodology}

The study employed a qualitative case study method which is known to have the capacity to investigate a contemporary phenomenon in depth and within its real life context (Yin, 2009). The study involved graduate students studying in the faculty of education in a university in Beijing and convenience sampling technique was used to identify the research participants. Convenience sampling involves choosing the nearest individuals to serve as respondents and continuing that process until the required sample has been obtained. Data was collected through in-depth interviews. According to Hays (2004), interviews are one of the richest sources of data in a case study and usually the most important type of data to be collected. Observation on how students use social media was also done. The interactional behavior of students on social media platform and in classroom was observed and analyzed.

Data collected was read through to obtain a general sense of the information as recommended by (Creswell, 2009). Based on research questions, detailed analysis was done to understand how students use social media platforms. This involved taking text data, segmenting them into categories and then labeling those categories with a term, usually a theme. Then description about the themes was done and the themes appeared as major findings of the study. Informed consent was sought from participants before they were interviewed and pseudonyms were used to hide the identity of the participants as advised by Cohen, Manion, and Morrison, (2007).

\section{Findings and Discussion}

The purpose of the study was to explore how students use social media platforms and the challenges associated with such usage. This part therefore discusses types of social media used by students, uses of such social media and the challenges associated with using such social media. 


\subsection{Type of Social Media}

There are several social media networks and instant messaging platforms that graduate students use, namely: Facebook, YouTube, LinkedIn, Twitter, WeChat and WhatsApp. WeChat and WhatsApp have similar features only that WeChat is mainly used in China and WhatsApp in other countries. WeChat is also more advanced as one can also perform money transactions and marketing activities while WhatsApp lacks these features. Most students have both accounts and have different categories of friends to correspond with using these platforms. Facebook, Twitter and YouTube are not mainly used by students because these platforms are not allowed in China. However, some students access them using VPN. LinkedIn is a professional networking site. Even though most students have accounts with LinkedIn, it was found that they do not usually use the platforms when compared to other platforms mentioned above.

\subsection{Uses of Social Media}

Social media can be used to perform both social and academic functions. This section therefore presents and discusses the findings of the study in relation to the uses of social media among students.

Social function - Users of social media usually use it to interact and chat with their friends and peers. Possibly that is the reason it was named social media in the first place. Social media allows participants to share moments with their friends, family and relations. Participants were found to use WhatsApp, WeChat and Facebook to connect and communicate with their family and friends back home. This supports Albert (2015) who argues that social media allows people to maintain connection with friends and family, and this reduces home sickness and stress which is common for students studying abroad. Participants were also found to use WeChat and WhatsApp to organize programs and disseminate information to other students about social activities. Participants argued that they reach out to many people at once if they share information about social activities via WeChat or WhatsApp as suggested by Albert (2015). It was also noted that these platforms facilitate social support among students. This supports the idea of Blaschke (2014); Luo (2010); Duta and Mertinez-Rivera (2014) that social media facilitates interaction among students by providing a dynamic platform that enables connections and social support, collaboration, discussions and organization of activities and events. This also ensures that communication is swift as face to face meeting is no longer a requirement which would otherwise consume a lot of time as suggested by Albert (2015). Social connections through the use of the different platforms facilitate community building among the students and according to West, Moore, and Barry (2015), this is very important for students success.

Academic function - Not only do students use social media for socializing. They also use social media to execute academic activities. Participants noted that they use these platforms to collaborate and work on group assignments. It was striking to note that soon after they are given group work, students form group chats on WeChat where sometimes they invite their instructor to be part of the group. Students share all academic activities pertaining to the group tasks. They also consult their instructors to seek clarification about tasks and assignments hence allowing students and instructors to connect during and after formal instructions as supported by Mannning and Johnson (2011). This results into interpersonal connections with their instructors which are seen to have an effect on academic success as argued by Young et al. (as cited in Nkhoma et al., 2015). Additionally, students update each other on issues relating to their theses, assignments and courses. As Duta and Mertinez-Rivera (2014) note, social media allows information exchange and the formation of communities resulting into a sense of belonging by all involved. One would also argue that social media provides a platform where students develop skills such as team work and tolerance as they interact with each other.

It was further noted that students use WeChat and Facebook to share links of questionnaires for their research projects which becomes easy and convenient for respondents to respond as they are not required to log in to a computer to answer the questionnaires. Respondents answer the questionnaires through the platform on their handsets. As such, it was learnt that response to questionnaires disseminated through this platform is always 
The potential of integrating social media as a learning tool among international graduate students in Beijing

high. One of the striking features of WeChat and WhatsApp is that once a message arrives, it notifies the reader and thus immediacy in responding to such messages is guaranteed. Similarly, even though Facebook is not allowed in China, most international students use this platform to execute academic related activities. Due to the high costs that students may incur to go back to their home countries for data collection for their theses, Facebook is used to distribute links for their questionnaires to targeted population. Facebook therefore allows students to have access to a wide range of information.

Students are also on record of sharing their success and projects on Facebook and thus learn from the comments given to such posts by their Facebook friends. One student indicated that after publishing a paper, he shared it online via Facebook for other scholars to make comments on it. Through such initiatives, one is able to use the social media as a learning platform. This supports the thought of Connectivism advanced by Siemens (2004) that through personal networks, learners can acquire the view point and diversity of opinions to learn to make critical decisions. However, it must be noted that most friends on Facebook are from their home countries and that might affect variety and quality of answers to topics under discussions. Nonetheless, connections are widening as students are exposed and make new friends via Facebook whilst in China. A connection through social media platforms therefore eases one's academic related work as distribution and access to materials becomes much easier than if not connected through these media platforms.

\subsection{Benefits of using Social Media}

The study has found that there are numerous benefits that students get as a result of using the social media and these are discussed in this section.

Equal voice - Through observation, it was noted that social media platforms especially WeChat which is mostly used by students whilst in china facilitates learning by granting students equal voice. When compared to face to face class discussion, it was observed that online group discussion through WeChat gives each student an equal voice. Introvert students when online never got interrupted or run out of time telling a story which was not possible in a classroom situation. Students therefore feel free to voice out their concerns when online than when in classroom situations. As such, integrating these platforms in the teaching and learning would personalize the learning process by appealing to each student type.

Quality of arguments - It was also found that the quality of points raised during online academic discussions was significantly high. This could be attributed to the fact that the students are aware that their posts would be seen by the whole class and as such they try to make sure that what they post is of high quality. One respondent had this to say: "when I post on group chat I am always serious because I know my teacher and classmates are reading it'. This entails that students subject their posts to intensive review and editing before they can post them and this process would help to improve the quality of argument compared to class discussions where editing one's argument is not possible. Again, there are situations where some students cannot properly express themselves to others in a way that others can understand. As such, writing through social media removes such face to face communication challenges. However, there were still some instances where some students could post comments that were not fruitful or related to topics under discussion. This could be attributed to such students' misunderstandings about a topic under discussion.

Enhancement of learning - Social media facilitates learning as services provided by these platforms allow students to have access to materials and instructors outside the formal schooling. Students were found to have access to their professors even out of the class situation and thus could ask clarifications and directions. It was also learnt that students use YouTube to download videos for their courses and learn new knowledge by themselves through those videos. Some students for example mentioned a scenario where they were to write a statistics examination. However they were not clear about some concepts and they resorted to using YouTube videos to teach them. Therefore teachers can exploit this opportunity by posting videos related to their courses on YouTube so that students can download and learn during their own free time. As noted by Mannning and 
Johnson (2011) social media is a place that is most likely familiar to their students hence integrating it would not be much challenging.

\subsection{Challenges}

Much as the study has found that social media is very important in the lives of students, their willingness to use it has the capacity to frustrate them and derail their academic focus. Therefore this section discusses issues that could be a source of frustration and also those issues that require serious consideration on the use of social media by the students.

Difficulty in accessing some social media platforms - The study has shown that students face numerous challenges regarding usage of some social media platforms. As already mentioned, some social media platforms like Facebook and YouTube are not allowed in China. To access these platforms requires VPN. However sometimes VPN is very difficult to connect. As such students find it difficult to use these platforms in their everyday life. Since the students are used to accessing such social media in their home countries without hassles it becomes frustrating for them in an environment where access is not allowed. Failure to access their accounts could be a source of stress to the students and this may affect their academic life.

Sharing of unwanted material and content - Some students join platforms such as Facebook, WeChat and WhatsApp using different names to hide their identity. As Mannning and Johnson (2011) state, users often create alternative identities within it and post pictures of people other than themselves in order to participate in these environments more anonymously. Such type of people sometimes post highly graphic materials and content that they would never mention aloud while looking their target in the eye. It was also observed that even though some students do not participate anonymously on these platforms, they tend to share information on the chat that is not related to the subject under discussion. There were instances where students could post videos and pictures on group WeChat that are not in any way related to the subject matter. This derails the whole purpose for which the chat was meant for as it tends to divert students attention away from the initial purpose they were there for. Again some students get irritated along the way in group chats and tend to withdraw defeating the whole purpose for which such platforms were created.

Effect on academic performance - It was observed that dividing time for social and academic purpose is difficult for a good number of students. Many of them were unable to properly use social media as they were found to engage in social media interaction while classes were in progress. This multitasking drives attention away from topics under discussion in a classroom situation. It was also noted that some students chat with multiple friends at the same time through these social media. As such sometimes it becomes difficult to concentrate on academic activities. This in a way has an effect on their academic performance. This confirms a study by Glogocheski (2015) who found a negative correlation between the amount of time spent on social media and their GPA. However, it could be argued that it is not the time spent on social media that negatively affects students' perfomance but rather it is the students' failure to properly divide their time between social and academic activities.

Effect on interpersonal skills - Even though social media increases access to other information and facilitates interaction, it reduces human contact. Most students were found to rely on social media for communication and spend less and less on human contact. Even in situations where students were in face to face group discussions, it was noted that they spend most of the time interacting with other friends and neglect those with whom they are sitting together on a discussion. This not only reduces interpersonal skills, a very important skill in the job market, but also irritates the facilitators who cannot command the attention of participants any more.

\section{Conclusions, Lessons and Recommendations}

Social media indeed has become an integral part of a student's life. Even though it has issues which need to 
The potential of integrating social media as a learning tool among international graduate students in Beijing be carefully looked into as indicated above, it has eased learners' life styles and facilitated their interactions. It has also exposed students to a great deal of information. This requires that educators embrace social media in the teaching and learning process. Indeed, as Magette (2013) states, educational professionals should not forget that students are already on social media sites and they are ready to engage with educators. What is required is for educators to integrate these social media in the teaching and learning process. This however will only be possible if enough is known about what kind of social media is used and for what purpose, and the impact of such social media on their students. As for this study, apart from social uses, students also use social media for academic purposes and it has proved to be an efficient way of academic interaction in situations where face to face interaction is not convenient. It has also been noted that students use social media as a medium to distribute questionnaires for their projects. They also use social media to connect with other professionals and get comments on their work. This study has therefore provided useful information that can help educators to think about possibilities of integrating social media platforms such as WeChat, WhatsApp, YouTube and Facebook in their teaching activities.

Acknowledgements: We would like to sincerely thank all our research participants for accepting to be part of this study. A vote of thanks should also be extended to our classmates for their encouragement and support during the time of this study.

\section{References}

Albert, D. J. (2015). Social media in music education: Extending learning to where students "live". Music Educators Journal, 102(2), 31-38. http://dx.doi.org/10.1177/0027432115606976

Bal, A. S., Grewal, D., Mills, A., \& Ottley, G. (2015). Engaging students with social media. Journal of Marketing Education, 37(3), 190-203. http://dx.doi.org/10.1177/0273475315593380

Beltran-Cruz, M., \& Cruz, S. B. (2013). The use of internet-based social media as a tool in enhancing students learning experiences in biological sciences. Higher Learning Research Communications, 3(4), 68-80. http://dx.doi.org/10.18870/hlrc.v3i4.170

Blaschke, L. M. (2014). Using social media to engage and develop the online learner in self-detemined Learning. Research in Learning Technology, 22, 1-23. http://dx.doi.org/10.3402/rlt.v22.21635

Cohen, L., Manion, L., \& Morrison, K. (2007). Research methods in education (6th ed.). Milton Park, USA: Routledge.

Creswell, J. W. (2009). Research design: Qualitative, quantitative, and mixed methods approaches (3rd ed.). London: Sage

Demirbilek, M. (2015). Social media and peer feedback: What do students really think about using Wiki and Facebook as platforms for peer feedback? Active Learning in Higher Education, 16(3), 211-224. http://dx.doi.org/10.1177/1469787415589530

Ding, F., \& Stapleton, P. (2015). Self-emergent peer support online social networking during cross-border Transition. Australasian Journal of Educational Technology, 31(6), 671-684.

Dron, J., \& Anderson, T. (2015). Learning and teaching with social media. In Kinshuk \& R. Huangs (Eds.), Ubiquitous learning environemets and technologies (pp. 15-30). Edmonton: Springer. http://dx.doi.org/10.1007/978-3-662-44659-1_2

Duke, B., Harper, G., \& Johnston, M. (2013). Connectivism as a digital age learning theory. The International HETL Review( Special Issue 2013), 4-13.

Duta, N., \& Mertinez-Rivera, O. (2014). Between theory and practice: The importance of ict in higher education as a tool for collaborative learning. Social and Behavioral Sciences, 1466-1473.

Glogocheski, S. W. (2015). social media usage and its impact on point average and retention: An exploratory study to generate viable strategies in a dynamic higher education learning environment. Unpublished Doctoral dissertation, St.John's University, New York. 
Kayange, J. J., \& Msiska, M.

Hays, P. A. (2004). Case study research. In K. deMarrais \& S. Lapan (Eds.), Foundations for research methods of inquiry in education and social sciences (pp. 217-234). New Jersey: Lawrence Erlbaum Associates, Publishers.

Johnson, J., \& Maddox, J. (2012). Use of social media in graduate education: An exploratory review for breaking new ground. Journal of Higher Education Theory and Practice, 12(3), 87-93.

Lenartz, A. J. (2012). All my rowday 'friends': The use of social media in higher education. Unpublished Doctoral dissertation, Northern Arizona University, Arizona

Luo, L. (2010). Social networking websites: An exploratory study of student peer socializing in an online LIS Program. Journal of Education for Library and Information Science, 51(2), 86-102.

Magette, K. (2013). Teachers talk about using social media. Educational Horizons, 92(2), 6-7.

Mannning, S., \& Johnson, K. E. (2011). The technology tool belt for teaching. San Francisco: Jossy-Bass.

May, T. (2015). Social media: A study of its use in higher education. Unpublished Doctoral dissertation, Grand Canyon University, Phoenix, Arizona.

McEwan, B. (2011). Hybrid engagement: How facebook helps and hinders students social intergration. Cutting-edge Technologies in Higher Education, 2, 3-23. http://dx.doi.org/10.1108/S2044-9968(2011)0000002004

Miron, E., \& Ravid, G. (2015). Facebook groups as an academic teaching aid: Case Study and recommendations for educators. Journal of Educational Technology and Society, 18(4), 371-384.

Murry, K. E., \& Waller, R. (2007). Social networking goes abroad. International Educator, 16(3), 56-63.

Nkhoma, M., Cong, H. P., Au, B., Lam, T., Richardson, J., Smith, R., \& El-Den, J. (2015). Facebook as a tool for learning purposes: Analysis of the determinants leading to improved students learnig. Active Learning in Higher Education, 16(2), 87-101. http://dx.doi.org/10.1177/1469787415574180

Siemens, G. (2004). Connectivism: A learning theory for the digital age. International Journal of Instructional Technologyand Distance Learning, 2(1), 3-10.

Sponcil, M., \& Gitimu, P. (2013). Use of social media by college students: Relationship to communication and self-concept. Journal of Technology Research, 4, 1- 13.

West, B., Moore, H., \& Barry, B. (2015). Beyond the tweet: Using Twitter to enhance engagement, learning, and success among first-year students. Journal of Marketing Education, 37(3), 160-170. http://dx.doi.org/10.1177/0273475315586061

Yin, R. K. (2009). Case study research, design and methods ( $4^{\text {th }}$ ed.). London: Sage. 